\title{
ANALISIS PERMASALAHAN GIZI BURUK BERDASARKAN INDIKATOR NUTRITION COMMITMENT INDEX (NCI) DI KABUPATEN BENGKULU UTARA
}

\author{
Analysis of Malnutrition Problems based on the Nutrition Commitment Index (NCI) \\ Indicator In North Bengkulu District \\ Veby Fransisca Rozi, Novega \\ Program Studi Kesehatan Masyarakat STIKes Bhakti Husada Bengkulu \\ Email : vebybengkulu@gmail.com
}

\begin{abstract}
Riskesdas Results of Bengkulu Province in 2013, the highest prevalence of malnourished children is in North Bengkulu Regency, which is $24.1 \%$. The number of cases of malnourished children under five in North Bengkulu Regency in 2015 was 20 people. One indicator to measure government commitment is to look at the Nurtition Commitment Index (NCI) indicator. NCI is an index to measure the government's commitment to addressing malnutrition with 12 indicators grouped into 3 themes namely budget, program policies and written regulations. Research purposes is to analyze the problem of malnutrition based on NCI indicators in North Bengkulu Regency. This study uses qualitative methods with policy study design. There were 5 informants in the study. The results showed that from 12 NC scores there were 7 indicators that had been achieved, namely vitamin A coverage indicators, access to clean water, nutritional program conditions in regional policies, nutrition programs prioritized in regional planning, cross-sector coordination, nutrition program indicator targets and nutrition surveys in 3 last year while the 5 indicators that are still not achieved are budget indicators, exclusive breastfeeding promotion, sanitation coverage, visit of pregnant women, namely K1 and K4 and legal indicators. It is recommended that the Health Service coordinate internally with the Health Service and with the budgeting team so that the proposed nutrition program budget plan can be realized to the full..
\end{abstract}

Keywords : Malnutrition, NCI Indicator, HANCI

\begin{abstract}
Abstrak
Hasil Riskesdas Provinsi Bengkulu Tahun 2013, prevalensi Balita gizi buruk tertinggi berada di Kabupaten Bengkulu Utara yaitu 24,1\%. Jumlah kasus Balita gizi buruk di Kabupaten Bengkulu Utara tahun 2015 sebanyak 20 orang. Salah satu indikator untuk mengukur komitmen pemerintah yaitu dengan melihat indikator Nurtition Commitment Index (NCI). NCI adalah indeks untuk mengukur komitmen pemerintah dalam mengatasi kekurangan gizi dengan 12 indikator yang dikelompokkan dalam 3 tema yaitu anggaran, kebijakan program dan regulasi tertulis. Tujuan penelitian untuk menganalisis permasalahan gizi buruk berdasarkan indikator NCI di Kabupaten Bengkulu Utara. Penelitian ini menggunakan metode kualitatif dengan rancangan penelitian studi kebijakan. Informan dalam penelitian berjumlah 5 orang. Hasil penelitian menunjukkan dari 12 skor NC terdapat 7 indikator yang sudah tercapai yaitu indikator cakupan vitamin A, akses air bersih, kondisi program gizi dalam kebijakan daerah, program gizi diprioritaskan dalam perencanaan daerah, koordinasi lintas sektor, target indikator program gizi dan survei gizi dalam 3 tahun terakhir sedangkan 5 indikator yang masih belum tercapai yaitu indikator anggaran, promosi ASI eksklusif, cakupan sanitasi, kunjungan ibu hamil yaitu K1 dan K4 dan indikator hukum. Disarankan Dinas Kesehatan mengadakan koordinasi antar intern Dinas Kesehatan maupun dengan tim penyusunan anggaran agar usulan rencana anggaran program gizi dapat terealisasi secara maksimal.
\end{abstract}

Kata kunci : Gizi Buruk, Indikator NCI, HANCI 


\section{PENDAHULUAN}

Kasus kekurangan gizi pada anak balita yang diukur dengan prevalensi anak balita gizi kurang dan gizi buruk digunakan sebagai indikator kelaparan, karena mempunyai keterkaitan yang erat dengan kondisi kerawanan pangan di masyarakat (BAPPENAS, 2011). Situasi gizi dunia menunjukkan dua kondisi yang ekstrem, mulai dari kelaparan sampai pola makan yang mengikuti gaya hidup yaitu rendah serat dan tinggi kalori, serta kondisi kurus dan pendek sampai kegemukan. Di sisi lain, penyakit menular dan penyakit tidak menular juga meningkat. Sangat jelas peran gizi berkontribusi bermakna pada penanggulangan ke dua jenis penyakit ini. Untuk mencapai status kesehatan yang optimal, dua sisi beban penyakit ini perlu diberi perhatian lebih pada pendekatan gizi, baik pada masyarakat kaya maupun pada kelompok masyarakat miskin (WHO, 2008).

Hal yang sama juga terjadi di Indonesia. Pada saat sebagian besar bangsa Indonesia masih menderita kekurangan gizi terutama pada ibu, bayi dan anak secara bersamaan masalah gizi lebih cenderung semakin meningkat dan berakibat beban ganda yang menghambat laju pembangunan. Status gizi optimal dari suatu masyarakat telah secara luas diterima sebagai salah satu dari prediktor untuk kualitas sumberdaya manusia, prestasi akademik, dan daya saing bangsa.

Kebijakan pemerintah untuk mengatasi masalah gizi terdapat pada Undang-Undang No. 17 tahun 2007 tentang Rencana Pembangunan Jangka Panjang Nasional tahun 2005-2025 menegaskan bahwa "Pembangunan dan perbaikan gizi dilaksanakan secara lintas sektor meliputi produksi, pengolahan, distribusi, hingga konsumsi pangan dengan kandungan gizi yang cukup, seimbang, serta terjamin keamanannya". Instruksi Presiden No. 3 Tahun 2010 menginstruksikan perlunya disusun Rencana Aksi Pangan dan Gizi Nasional dan Rencana Aksi Pangan dan Gizi di tingkat provinsi yang dalam proses penyusunannya melibatkan kabupaten dan kota. Adanya Rencana Aksi Pangan dan Gizi Nasional ini diharapkan masalah gizi buruk dan gizi kurang dapat diatasi, namun pada kenyataannya terjadi pening- katan pada prevalensi gizi buruk ditahun 2013 (BAPPENAS, 2011).

Status Gizi Balita menurut indikator BB/U secara nasional, prevalensi berat-kurang pada tahun 2013 adalah 19,6 persen, terdiri dari 5,7 persen gizi buruk dan 13,9 persen gizi kurang. Jika dibandingkan dengan angka prevalensi nasional tahun 2007 $(18,4 \%)$ dan tahun 2010 (17,9\%) terlihat meningkat. Perubahan terutama pada prevalensi gizi buruk yaitu dari 5,4 persen tahun 2007, 4,9 persen pada tahun 2010, dan 5,7 persen tahun 2013 (Riskesdas 2013). Hasil Riskesdas Provinsi Bengkulu Tahun 2013, prevalensi Balita gizi buruk tertinggi berada di Kabupaten Bengkulu Utara yaitu 24,1\%. Sedangkan jumlah kasus Balita gizi buruk yang ditemukan di Kabupaten Bengkulu Utara tahun 2015 adalah sebanyak 20 orang.

Tingginya kasus gizi buruk di Kabupaten Bengkulu Utara merupakan tantangan bagi Pemerintah. Masalah gizi buruk dan gizi kurang memiliki efek sosial dan ekonomi serta menggagalkan upaya penanggulangan kemiskinan. Komitmen pemerintah dalam mengatasi masalah gizi di Kabupaten Bengkulu Utara sangat diperlukan. Salah satu indikator untuk mengukur komitmen pemerintah yaitu dengan melihat pencapaian program, regulasi tertulis dan anggaran yang disediakan dari pemerintah setempat terkait dengan masalah gizi.

Kebijakan mengenai perbaikan gizi ditingkat Provinsi Bengkulu terdapat dalam Perda Nomor 12 tahun 2013 tentang perbaikan gizi dengan maksud dan tujuan untuk meningkatkan status gizi, pengetahuan dan kesadaran masyarakat tentang pentingnya gizi dan pengaruhnya terhadap peningkatan status gizi, pelayanan gizi komunitas dan pelayanan gizi pada penyakit degeneratif. Namun untuk ditingkat Kabupaten Bengkulu Utara belum ada regulasi tertulis mengenai masalah perbaikan gizi.

Komitmen pemerintah Kabupaten Bengkulu Utara dalam mengatasi masalah gizi buruk tentunya harus diukur melalui indikator-indikator. The Hunger and Nutrition Commitment Index (HANCI) merupakan salah satu metode untuk mengukur komitmen pemerintah dalam mengatasi kelaparan dan masalah 
gizi berdasarkan 22 indikator. Indikator dibagi antara indikator komitmen pengurangan kelaparan (HRCI) yaitu 10 indikator dan indikator yang berkaitan dengan komitmen untuk mengatasi kekurangan gizi (NCI) 12 indikator. Masing-masing set dikelompokkan dalam 3 tema yaitu hukum, kebijakan dan pengeluaran / anggaran (Lintelo, et.al, 2015).

Hasil HANCI dan NCI tahun 2014, Indonesia termasuk dalam indeks menengah yaitu peringkat 10 dari 45 negara dengan skor 188 untuk HANCI dan skor 109 untuk NCI. Dari 12 indikator, terdapat 2 indikator komitmen pemerintah dalam mengatasi masalah gizi dengan skor rendah yaitu pada indikator cakupan vitamin A $(82 \%)$ dan indikator akses terhadap air minum bersih $(84,9 \%)$, selain itu terdapat 2 indikator dengan skor sangat rendah yaitu pada indikator akses sanitasi $(58,8 \%)$ dan indikator program gizi dalam kebijakan pembangunan nasional lemah (Lintelo, et.al, 2015). Tujuan penelitian untuk menganalisis permasalahan gizi buruk berdasarkan indikator NCI di Kabupaten Bengkulu Utara

\section{BAHAN DAN METODE}

Penelitian ini menggunakan metode kualitatif dengan rancangan penelitian studi kebijakan (Policy study), dan juga dilakukan skoring serta wawancara pada informan untuk mengetahui informasi yang mendalam tentang komitmen perintah dalam mengatasi masalah gizi di Kabupaten Bengkulu Utara. Informan pada penelitian ini adalah Kepala Dinas Kesehatan Kabupaten Bengkulu Utara, Kepala Bidang peningkatan pelayanan kesehatan Dinas Kesehatan Bengkulu Utara, Kepala Seksi Keuangan Dinas Kesehatan Kabupaten Bengkulu Utara, Kepala Seksi Gizi dan Kesehatan Keluarga Dinas Kesehatan dan Kepala Seksi Perencanaan Dinas Kesehatan Kabupaten Bengkulu Utara.

\section{HASIL DAN PEMBAHASAN}

\section{Komponen Input \\ Pengeluaran/Anggaran}

Berikut ini pernyataan dari informan terhadap komitmen Pemerintah Kabupaten Bengkulu Utara dalam mengatasi permasalahan gizi buruk berdasarkan indikator kecukupan pengeluaran/ anggaran.
"Untuk anggaran program gizi ini berasal dari APBD Kabupaten Bengkulu Utara ada juga yang dari $A P B N$. Proses penyusunanyapun dimulai dari Dinas Kesehatan menyusun prioritas anggaran berdasarkan rencana kerja. Untuk anggaran program gizi ini sepertinya masih kurang. Dana yang sudah ada harus diefisienkan penggunaanya untuk kegiatan-kegiatan seperti pemberian PMT. Untuk menanggulangi gizi buruk tentu banyak kegiatan yang dilakukan mulai dari pencegahan sampai dengan penanngulangan. Untuk anggaran kegiatan sekarang lebih terfokus pada kegiatan penanggulangan, sedangkan untuk langkah pencegahan gizi buruk masih sangat minim seperti pemberian vitamin bagi bayi dan balita dan pelatihan tenaga gizi. Kegiatan itu belum maksimal dilakukan karena anggaran yang masih belum cukup. Semoga ditahun berikutmya kegiatankegiatan itu bisa terealisasi dengan penambahan anggaran pada program gizi ini. (Informan 3)

Pernyataan di atas menunjukkan bahwa untuk anggaran gizi di Dinas Kesehatan Kabupaten Bengkulu Utara masih kurang. Dalam UU Keuangan Negara No. 17 Tahun 2003 menyebutkan anggaran daerah merupakan rencana keuangan yang menjadi dasar dalam pelaksanaan pelayanan publik. Di Indonesia, dokumen anggaran daerah disebut Anggaran Pendapatan dan Belanja Daerah (APBD), baik untuk provinsi maupun kabupaten dan kota. Anggaran Pendapatan dan Belanja Daerah (APBD) pada hakekatnya merupakan salah satu instrumen kebijakan yang dipakai sebagai alat untuk meningkatkan pelayanan umum dan kesejahteraan masyarakat di suatu daerah. Di dalam APBD tercermin kebutuhan masyarakat dengan memperhatikan potensi dan sumber-sumber kekayaan daerah. Hasil penelitian Laksmiarti (2013) menunjukkan bahwa sumber pembiayaan terbesar di Kabupaten Kepulauan Aru berasal dari pemerintah yaitu 91,95\% (APBD kabupaten 81,60\% dan APBN 9,31\%).

\section{Kebijakan/Program}

Informasi mengenai pencapaian cakupan program vitamin A, Promosi ASI eksklusif, akses air bersih, akses sanitasi, kunjungan, ibu hamil (K1 dan K4), program gizi dalam kebijakan daerah, prioritas gizi dalam perencanaan daerah, kerjasama multi sektor dan koordinasi multi stakeholder, target nutrisi dan survei gizi nasional dalam 3 tahun terakhir di 
Dinas Kesehatan Kabupaten Bengkulu Utara adalah sebagai berikut.

"Pencapaian vitamin A sudah sangat baik dan melebihi target yaitu untuk bayi sudah mencapai 93,52\%, balita 92,18\%, bayi dan balita 92,40\%. Secara umum semua pencapaian sudah melebihi target, namun memang ada beberapa daerah yang masih dibawah target pencapaian vitamin A nya yaitu Kecamatan napal putih 72,19\%. Rendahnya pengetahuan ibu akan pentingnya vitamin A ini sangat mempengaruhi keberhasilan pemberian vitamin A selain itu ibu-ibu yang bekerja sebagai petani kesulitan dalam mengatur waktu Posyandu sehingga menyebabkan bayi dan balitanya tidak diberikan vitamin A. Untuk mengatasi masalah ini kami akan terus meningkatkan pelayanan gizi khususnya pemberian vitamin A ke daerah-daerah terpencil" (Informan 4)

"Promosi ASI eksklusif tentu saja terus dilakukan oleh bidan maupun perawat yang bertugas saat jadwal imunisasi baik di Puskesmas maupun di Posyandu. Pencapaian jumlah bayi yang diberi ASI eksklusif di Kabupaten Bengkulu Utara tahun 2017 masih cukup rendah yaitu sekitar 58\% dari total sekitar 1.290 bayi yang ada. Kesadaran dan pemahaman ibu disini sangat mendukung keberhasilan pemberian ASI eksklsif ini, sehingga untuk mengatasinya petugas kesehatan saat kegiatan imuniasasi selalu memberikan penyuluhan kepada ibu-ibu untuk memberikan ASI eksklusif pada bayinya" (Informan 2)

"Penduduk dengan akses air minum layak di Kabupaten Bengkulu Utara Alhamdulillah sudah baik sudah lebih dari $80 \%$. Jumlah penduduk sekitar 285 ribu dan sebagian besar menngunakan sumber air dari PDAM" (Informan 2)

"Pencapaian penduduk dengan akses sanitasi layak (jamban sehat) tahun 2017 belum memenuhi target karena baru mencapai 66,8\%. Kesadaran masyarakat untuk memiliki jamban sehat dan rendahnya pendapatan keluarga mempengaruhi kepemilikan jamban sehat ini. Untuk daerah Hulu palik dan arma jaya misalnya, disana banyak warga yang belum memiliki jamban karena memanfaatkan sungai untuk keperluan MCK" (Informan 4)

"Kunjungan ibu hamil mencakup kunjungan K1 dan K4 sudah tercapai dengan baik hampir 100\%, begitu juga dengan persalinan yang ditolong oleh tenaga kesehatan kita sudah mencapai sekitar 90\% an. Pencapaian ini tidak terlepas dari peran bidan baik bidan yang ada di Puskesmas maupun bidan desa. Walaupun memang belum $100 \%$ pencapaian Kid an K4 namun yang telah dicapai saat ini sudah sangat baik" (Informan 2)

"Untuk kebijakan mengenai program gizi ini tentunya sudah diatur dalam kebijakan pusat dan provinsi. Sejauh ini program gizi menjadi salah satu prioritas program dalam rencana strategis dinas kesehatan kabupaten Bengkulu utara. Hanya saja perlu peningkatan kegiatan-kegiatan yang sifatnya mencegah dalam meningkatkan program gizi itu sendiri" (Informan 2)

"Program gizi ini diprioritaskan atau tidak oleh pemerintah tentu ada pertimbangannya, salah satunya bagaimana abesaran permasalahannya dan bagaimana cara menyelesaikan masalahnya. Permasalahan gizi ini diprioritaskan juga oleh kebijakan pemerintah Kabupaten Bengkulu Utara. Dengan adanya dukungan ini, alhasil masalah gizi inipun dapat diturunkan dari tahun ke tahunnya" (Informan 2)

"Pasti ada kerjasama dan koordinasi lintas sektor terkait, bidang gizi ini terus berkoordinasi dengan bupati, $D P R D$ dan bappeda terkait prioritas program dan anggaran program. Lintas sector lainnya seperti dinas ketahanan pangan dan dinas pertanian dan masih banyak lagi dinas terkait lainnya" (Informan 1)

"Target program gizi ada dari tahun-ketahun kadangkala berbeda. Target dalam program gizi ini ditentukan baik yang ada dalam SPM maupun target dinas. Target ini digunakan sebagai bahan evaluasi program agar dapat ditingkatkan dari tahun ke tahunnya. Kegiatan-kegiatan yang menunjang gizi seperti ASI eksklusif misalnya ada target yang ditentukan sebesar 90\%" (Informan 4)

"Riskesdas 2018 barusan ini mensurvei permasalah gizi di Kabupaten Bengkulu Utara. Namun untuk di dinas kesehatan sendiri survey belum dilakukan" (Informan 2)

Thomas Dye menyebutkan kebijakan sebagai pilihan pemerintah untuk melakukan atau tidak melakukan sesuatu (whatever government chooses to do or not to do). Friedrich mengatakan bahwa yang paling pokok bagi suatu kebijakan adalah adanya tujuan (goal), sasaran (objective) atau kehendak (purpose) (Abidin, 2002). Kebijakan kesehatan merupakan pedoman yang menjadi acuan bagi semua pelaku pembangunan kesehatan, baik 
pemerintah, swasta, dan masyarakat dalam penyelenggaraan pembangunan kesehatan dengan memperhatikan kerangka desentralisasi dan otonomi daerah (Depkes RI, 2009). Penelitian Sartika (2010) menyatakan untuk mengatasi masalah gizi pada anak usia di bawah lima tahun dibutuhkan kebijakan yang terfokus memulihkan pertumbuhan dan status kesehatan anak usia di bawah lima tahun dengan korelasi antara program gizi dan program lain, seperti kesehatan lingkungan dan imunisasi.

\section{Hukum}

Informasi mengenai hukum yang terkait dengan program gizi dalam kebijakan Pemerintah Kabupaten Bengkulu Utara adalah sebagai berikut.

"Sepertinya belum ada peraturan tertulis khusus tentang program gizi ini dibuat dalam Perbup atau perda kabupaten. Pemerintah daerah masih merujuk pada peraturan daerah provinsi nomor 12 tahun 2013 tentang perbaikan gizi. Peraturan provinsi ini sejauh ini belum diturunkan dalam peraturan tingkat kabupaten (Informan 2)

Hierarki dari peraturan perundang-undangan diatur dalam Pasal 7 Undang-Undang Nomor 12 Tahun 2011 tentang Pembentukan Peraturan Perundang-Undangan yang menentukan bahwa jenis dan hierarki peraturan perundang-undangan terdiri atas Undang-Undang Dasar Negara Republik Indonesia Tahun 1945, Ketetapan Majelis Permusyawaratan Rakyat, Undang-Undang/ Peraturan Pemerintah Pengganti Undang-Undang, Peraturan Pemerintah, Peraturan Presiden, Peraturan Daerah Provinsi dan Peraturan Daerah Kabupaten/ Kota.

Peraturan tentang perbaikan gizi di Provinsi Bengkulu terdapat dalam Peraturan Daerah Provinsi Bengkulu Nomor 12 Tahun 2013 tentang perbaikan gizi. Perbaikan gizi dimaksudkan untuk meningkatkan status gizi, pengetahuan dan kesadaran masyarakat tentang pentingnya gizi dan pengaruhnya terhadap peningkatan status gizi, pelayanan gizi komunitas dan pelayanan gizi pada penyakit degeneratif (Pasal 2 Perda No 12 Prov. Bengkulu tahun 2013).

\section{Skor NC}

Tabel 1. Skor NC Di Kabupaten Bengkulu Utara

\begin{tabular}{llc}
\hline No & Topik & Skor NC \\
\hline 1 & Pengeluaran/ Anggaran & 0 \\
2 & Cakupan Vitamin A & 1 \\
3 & Promosi ASI Eksklusif & 0 \\
4 & Akses Air Bersih & 1 \\
5 & Akses Sanitasi & 0 \\
6 & Kunjungan Ibu Hamil & 0 \\
7 & Kondisi Program Gizi dalam & 1 \\
& kebijakan daerah & \\
8 & Program Gizi diprioritaskan & 1 \\
& dalam perencanaan daerah & 1 \\
9 & Koordinasi Lintas Sektor & 1 \\
10 & Target Indikator Program Gizi & 1 \\
11 & Survei Gizi dalam 3 tahun & \\
& takhir & 0 \\
\hline 12 & Hukum (regulasi tertulis) & 7 \\
\hline
\end{tabular}

Berdasarkan tabel 1 di atas diketahui bahwa SKOR NC di Kabupaten Bengkulu Utara adalah 7. Dimana skor 0 diantaranya adalah pada indikator anggaran, promosi ASI eksklusif, cakupan sanitasi (jamban sehat), kunjungan ibu hamil yaitu K1 dan K4 dan indikator hukum.

Hasil HANCI tahun 2014, didapatkan bahwa Negara Peru menduduki peringkat kedua untuk NCI. Sedangkan, Indonesia termasuk dalam komitmen menengah yaitu peringkat 10 dari 45 negara (Lintelo, et.al, 2015). Penelitian Rozi (2016), SKOR NCI di Kota Bengkulu adalah 9 dari 12 indikator. Dimana skor 0 diantaranya adalah pada indikator anggaran, cakupan akses air bersih di Kota Bengkulu belum mencapai target dan kunjungan ibu hamil yaitu K1 dan K4 di Kota Bengkulu belum mencapai target nasional.

\section{KESIMPULAN DAN SARAN}

Dari 12 skor NCI terdapat 7 indikator yang sudah tercapai yaitu indikator cakupan vitamin A, akses air bersih, kondisi program gizi dalam kebijakan daerah, program gizi diprioritaskan dalam perencanaan daerah, koordinasi lintas sektor, target indikator program gizi dan survei gizi dalam 3 tahun 
terakhir sedangkan 5 indikator yang masih belum tercapai yaitu pada indikator anggaran, promosi ASI eksklusif, cakupan sanitasi (jamban sehat), kunjungan ibu hamil yaitu K1 dan K4 dan indikator hukum. Disarankan kepada Dinas Kesehatan mengadakan koordinasi antar intern Dinas Kesehatan maupun dengan tim penyusunan anggaran agar usulan rencana anggaran program gizi dapat terealisasi secara maksimal.

\section{UCAPAN TERIMA KASIH}

Penulis mengucapkan terima kasih kepada semua pihak yang telah membantu dalam penelitian ini terkhusus untuk Direktorat Riset dan Pengabdian kepada Masyarakat (DRPM) Direktorat Jenderal Penguatan Riset dan Pengembangan Kementerian Riset, Teknologi, dan Pendidikan Tinggi.

\section{DAFTAR PUSTAKA}

Bappenas., 2011. Rencana Aksi Nasional Pangan dan Gizi 2011-2015. Jakarta: Bappenas.

Departemen Kesehatan., 2009. Panduan Manajemen Suplemen Vitamin A. Jakarta: Direktorat BinaGizi Masyarakat.

Dinkes Provinsi Bengkulu., 2015. Profil Kesehatan Provinsi Bengkulu Tahun 2015. Bengkulu: Dinas Kesehatan Provinsi Bengkulu.

Kemenkes RI., 2013. Riset Kesehatan Dasar Tahun 2013. Jakarta: Balitbang Kemenkes RI.

Laksmiarti, Turniani., 2013. Analisis Pembiayaan Kesehatan Di Kabupaten Kepulauan Aru.
Surabaya: Buletin Penelitian Sistem Kesehatan

- Vol. 16 No. 3 Juli 2013: 321-329.

Lintelo,D.J.H., Haddad, L.J., Lakshman, R., Gatellier, K., 2014. The Hunger and Nutrition Commitment Index (HANCI 2013). England: Institute of Development Studies.

2015. The Hunger and Nutrition Commitment Index (HANCI 2014). England: Institute of Development Studies.

Parson, W., 2001. Public Policy (Penerjemah Tri Wibowo Budi Santoso). Jakarta: Kencana Prenada Media Group.

Pemprov Bengkulu., 2013. Peraturan Daerah Provinsi Bengkulu No 12 Tahun 2013 tentang Perbaikan Gizi. Bengkulu: Pemerintah Provinsi Bengkulu.

Republik Indonesia., 2003. Undang-Undang Nomor 17 Tahun 2003 tentang Keuangan Negara. 2009. Undang-Undang Nomor 36 Tahun 2009 tentang Kesehatan. , 2011. Undang-Undang Nomor 12 Tahun 2011 tentang Pembentukan Peraturan Peundang-Undangan.

Rozi, V.F., 2016. Analisis Komitmen Pemerintah Kota Bengkulu dalam Mengatasi Masalah Gizi berdasarkan Nutrition Commitment Index (NCI). Padang: Tesis Universitas Andalas.

Sartika, Ratu Ayu Dewi, 2010. Analisis Pemanfaatan Program Pelayanan Kesehatan Status Gizi Balita. Jakarta: Jurnal Kesehatan Masyarakat Nasional Vol. 5, No. 2, Oktober 2010.

UNICEF., 1998. The State of The World's Children 1998. New York: Oxford University Press.

WHO. 2008. The Global Nutrition Challenge: Getting a Healthy Start. The Pacific Health Summit. 